\title{
Métodos de seleção de plantas de maracujazeiro-azedo para a produç̧ão de sementes
}

\author{
Diego Adílio da Silva', Henrique Belmonte Petry², Emílio Della Bruna ${ }^{3}$ e Alexsander Luís Moreto²
}

\begin{abstract}
Resumo - A perda de características de importância agronômica do maracujazeiro-azedo (Passiflora edulis Sims.), por ser uma espécie alógama autoincompatível, pode ocorrer em poucos anos se a seleção dos frutos para a obtenção de sementes não for realizada corretamente. Este trabalho apresenta metodologias de seleção para a conservação dos genótipos locais, visando manter e aumentar a frequência alélica das características de interesse econômico dos cultivares e a produção de maracujáazedo de alta qualidade, em Santa Catarina.
\end{abstract}

Termos para indexação: Passiflora edulis; melhoramento genético; seleção massal.

\section{Selection methods of sour passion fruit plants for seed production}

Abstract - The loss of characteristics of agronomic importance for sour passion fruit (Passiflora edulis Sims.), for being selfincompatible allogamous species, can occur in few years if the selection method of the fruits to obtain seeds is not performed in the correct way. This study shows selection methodologies for the conservation of the local genotypes, aiming at maintaining and increasing the allele frequency of the characteristics of economic interest of the cultivars, and the production of highquality sour passion fruit in the state of Santa Catarina, Brazil.

Index terms: Passiflora edulis; breeding; mass selection.

\section{Introdução}

O maracujazeiro é uma planta alógama e entomófila. Por isso, a polinização é um dos fatores que mais influenciam a sua frutificação (BRUCKNER et al., 2002). As flores são hermafroditas e abrem uma única vez. Não ocorrendo a fecundação, as flores murcham e caem (SOUZA \& PEREIRA, 2011). Por se tratar de uma espécie alógama autoincompatível, a perda de algumas características adaptativas locais e que possam estar presentes na população de interesse pode ocorrer em poucos anos se a seleção dos frutos para a obtenção de sementes não for realizada corretamente. Desta forma, ter conhecimento do comportamento dos genitores que darão origem às sementes se torna imprescindível para evitar que características indesejáveis sejam perpetuadas nas populações subsequentes, além da perda de caracteres desejados.
A seleção massal é um método eficiente para a seleção de características de fácil mensuração e herdáveis, principalmente em populações de plantas que exibem alta variabilidade, como o maracujazeiro-azedo (MELETTI et al., 2005). Por exemplo, SCS437 Catarina (Figura 1) é um cultivar de polinização aberta, obtido através de seleção massal recorrente (BORÉM \& MIRANDA, 2009), o que permite a produção de sementes pelo próprio produtor, diferentemente dos cultivares híbridos disponíveis no mercado produzidos a partir de plantas matrizes clonadas com polinização dirigida, para as quais não há recomendação para a produção própria de sementes (JESUS et al., 2017).

\section{Seleção de plantas e frutos doadores de sementes}

Para o produtor produzir as suas próprias sementes de cultivares de po- linização aberta, os frutos doadores de sementes devem ser selecionados de plantas diferentes, de preferência de distintos talhões e/ou pomares que cultivem o mesmo cultivar, e assim compor o total de sementes necessárias para a produção de mudas. $O$ número de plantas selecionadas varia de acordo com o tamanho do pomar, porém, orienta-se que se selecione pelo menos vinte genitores de alta qualidade (JUNGHANS et al., 2017).

A escolha de frutos próximos ao centro da planta (indicador de precocidade), de tamanho e formato adequado, coloração da casca de acordo com o desejado e que estejam em plantas com boa carga produtiva e baixa incidência de pragas e doenças, leva à manutenção, e até ao melhoramento, das características agronômicas dos materiais locais, devendo os produtores de mudas estarem conscientes destas necessidades (JUNGHANS et al., 2017). A sele-

Recebido em 14/8/2018. Aceito para publicação em 26/11/2018.

http://dx.doi.org/10.22491/RAC.2019.v32n2.3 1 Engenheiro-agrônomo, Epagri/Escritório municipal de Meleiro, Rua Vinte de Dezembro, 212, bairro Estreito, 88920-000 Meleiro, SC, e-mail: diegosilva@ epagri.sc.gov.br.

2 Engenheiro-agrônomo, Dr., Epagri/Estação Experimental de Urussanga, Rodovia SC 108, km 353, 1563, bairro Estação, $88840-000$ Urussanga, SC, e-mail: henriquepetry@epagri.sc.gov.br, alexsandermoreto@epagri.sc.gov.br.

${ }^{3}$ Engenheiro-agrônomo, M. Sc., Epagri/Estação Experimental de Urussanga, Rodovia SC 108, km 353, 1563, bairro Estação, $88840-000$ Urussanga, SC, e-mail: emilio@epagri.sc.gov.br. 
ção deverá ocorrer em pomares de primeiro ano, diminuindo assim os riscos de transmissão de doenças (fungos e bactérias) pelas sementes e com maior pressão de seleção para as características de precocidade e de qualidade dos frutos no início da safra, período que melhor remunera o produtor (GOULART JÚNIOR et al., 2017).

Os materiais necessários para aplicação da metodologia nos pomares são fitas coloridas para marcação nas plantas selecionadas de cada uma das características avaliadas, sacos de papel kraft e sacos tipo raschel. Para a avaliação da qualidade dos frutos é necessário ter um paquímetro, uma balança e um refratômetro.

Cinco objetivos são destacados como os principais para manter as características comerciais do maracujáazedo, atribuindo-se uma cor de fita para cada característica, para facilitar a distinção das plantas selecionadas a campo:

a) Produtividade: plantas com carga produtiva superior, principalmente no início da safra;

b) Sanidade: ausência de folhas e frutos com incidência das principais doenças da cultura na região;

c) Qualidade do fruto: frutos com bom padrão comercial para comercialização in natura;

d) Precocidade: florescimento e produção precoce;

e) Vigor: entrenós curtos, plantas compactas e produtivas.

Resumidamente, a seleção de plantas matrizes e frutos para obtenção de sementes de maracujá deve seguir os sete itens descritos a seguir, baseado no método de seleção massal estratificada:

1. Dividir o pomar em duas ou quatro partes: essa estratificação do pomar visa minimizar as influências do ambiente que podem levar a possíveis confundimentos na seleção das plantas, por causa de manchas de solo, por exemplo.

2. No início da floração, selecionar em cada uma das partes divididas do pomar as primeiras plantas que floresceram (Figura 2a) e que fixaram frutos (Figura 2b), sendo essas marcadas com fitas. Esses são indicadores de precocidade;

3. No início da colheita, as plantas de cada parte do pomar deverão ser $>$ harvested fully ripe the plant

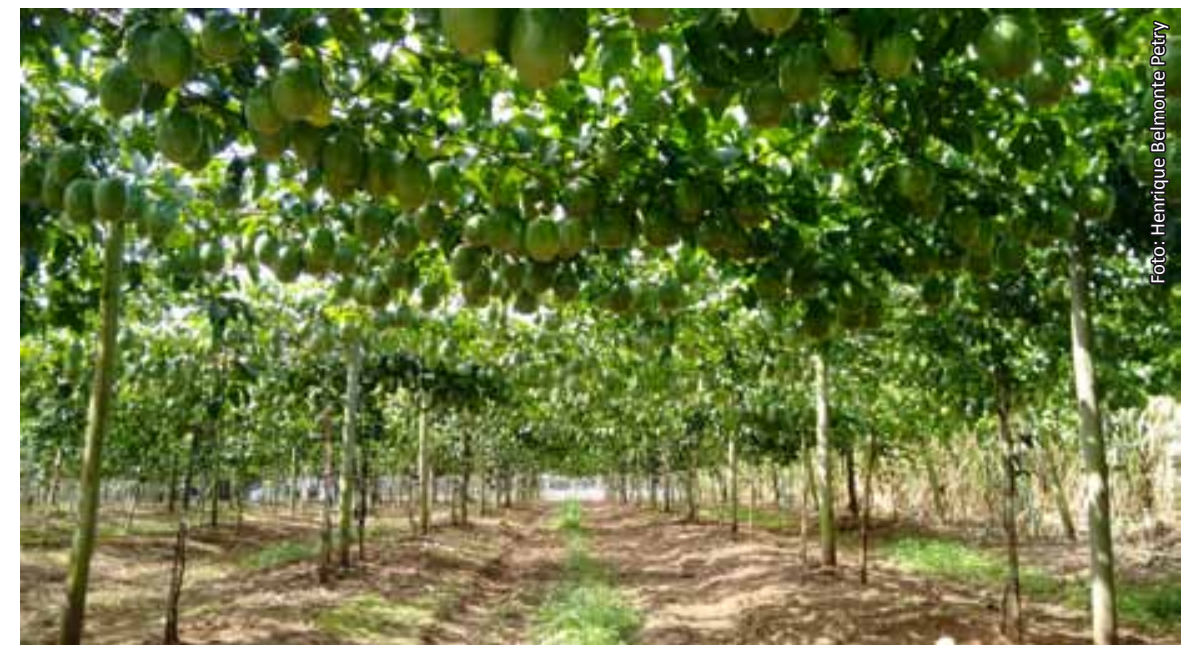

Figura 1. Pomar de maracujazeiro-azedo SCS 437 Catarina no município de São João do Sul, SC Figure 1. Orchard of passion fruit SCS 437 Catarina in the municipality of São João do Sul, SC

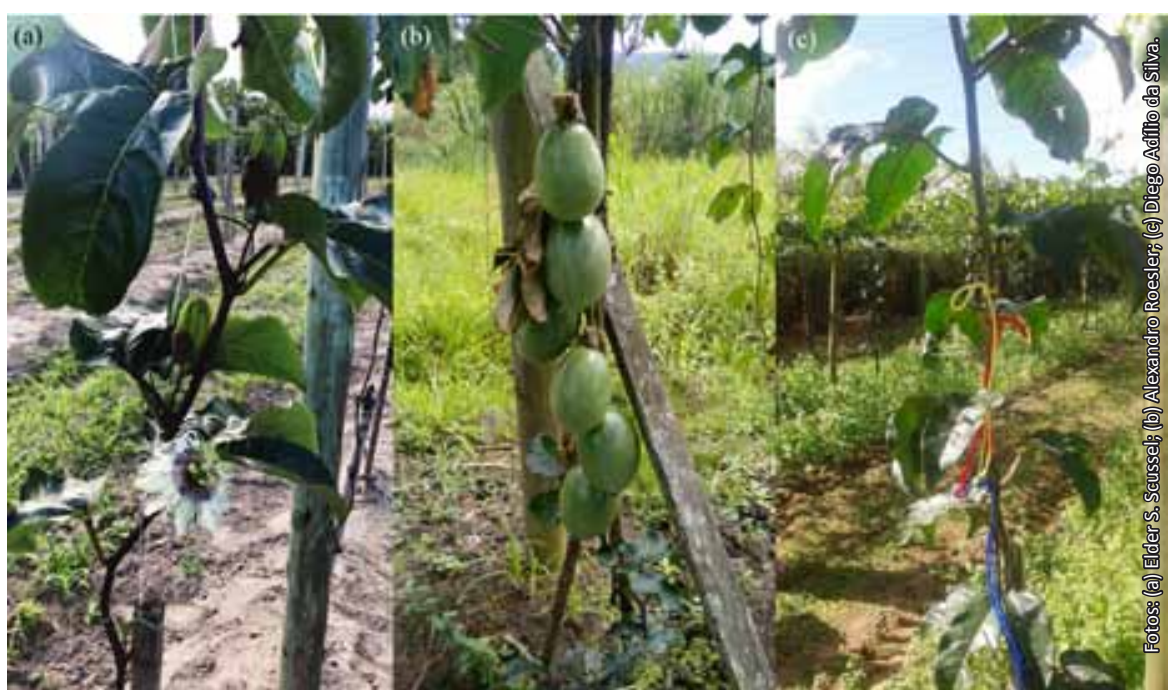

Figura 2. Plantas de maracujazeiros SCS 437 Catarina selecionadas quanto: (a) ao florescimento; (b) à produção precoce; (c) por superioridade em quatro características conforme indicam as fitas amarradas na planta

Figure 2. Plants of passion fruit 'SCS 437 Catarina' selected for: (a) flowering; (b) early production; (c) by superiority in four characteristics as indicated by the tapes attached to

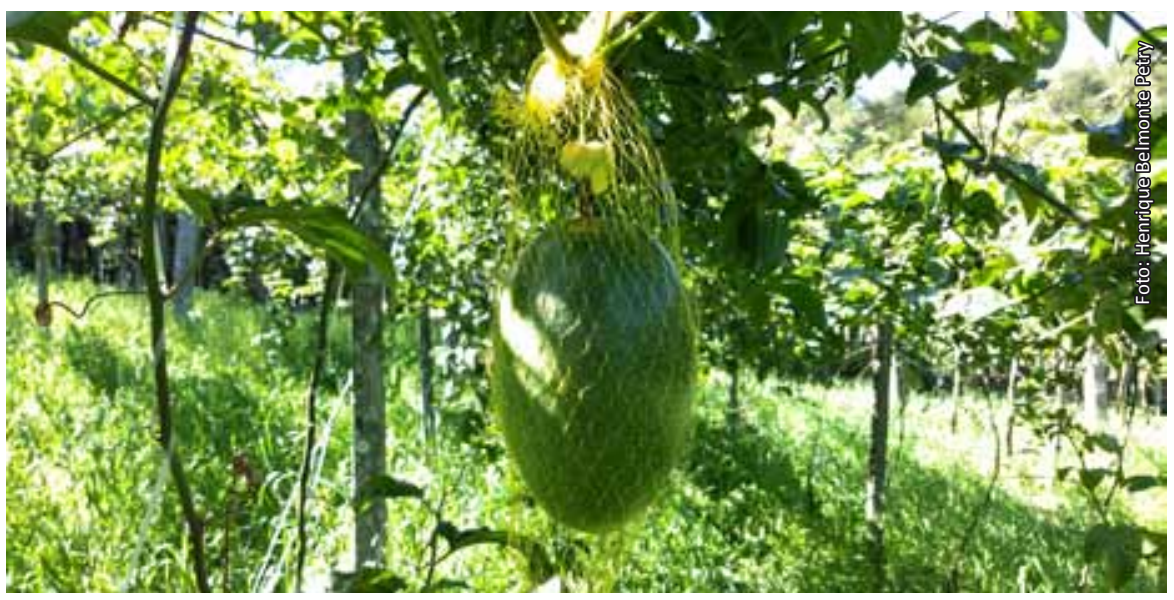

Figura 3. Maracujá-azedo SCS 437 Catarina selecionado com sacos tipo raschel, para ser colhido totalmente maduro

Figure 3. Sour passion fruit 'SCS 437 Catarina' selected with raschel type bags, to be 
avaliadas e marcadas conforme as suas características, principalmente quanto à produtividade, sanidade, qualidade - referente ao tamanho e formato dos frutos - e vigor;

4. Somente deverão ser coletados os frutos das plantas selecionadas que contenham mais de três fitas (Figura 2c), indicando que são superiores em pelo menos três características distintas. Deverão ser colhidos os frutos mais próximos ao centro da planta matriz. Também deve-se coletar o mesmo número de frutos por matriz selecionada;

5. Durante o processamento dos frutos para obtenção das sementes, avaliar a durabilidade dos frutos em temperatura ambiente (vida de prateleira), eliminando os frutos que murcham e/ou apresentam doenças pós-colheita até dez dias após a colheita;

6. Os frutos selecionados devem ser avaliados quanto a sua qualidade interna. Devem ter rendimento de polpa (com semente) superior a $40 \%$, conteúdo de açúcares superior a $11^{\circ}$ brix, acidez, espessura da casca entre 7 e $10 \mathrm{~mm}$ e cor da polpa alaranjada.

7. A separação do arilo das sementes pode ser realizada por vários métodos, tais como: fricção manual em maIha de arame, utilização de pós-secantes (cal, farinha de milho etc.) e fermentação da polpa, entre outras. Em geral, desde que não haja danos às sementes (ocasionado por lâminas de liquidificador, por exemplo), podem ser utilizados os diferentes métodos sem que haja prejuízo na germinação e viabilidade das sementes (MARTINS et al., 2006). As sementes devem ser secadas à sombra e posteriormente armazenadas em temperatura entre 4 e $8^{\circ} \mathrm{C}$ (geladeira), dentro de sacos plásticos amarrados.

Uma forma de acelerar os ganhos no processo é com a utilização do método de seleção recorrente entre progênies de irmãos completos (BORÉM \& MIRANDA, 2009). Nesse caso, é indicada a realização de cruzamento dirigido entre as matrizes selecionadas. Deve ser adicionado um passo no processo de seleção anteriormente descrito, antes da colheita dos frutos (item $n^{\circ} 4$ ): proteger as flores antes de sua abertura (antese), no período da manhã, com sacos de papel (kraft), e realizar a polinização somente com pólen de flores previamente isoladas (ensacadas), evitando a contaminação por pólen não desejado durante polinização natural pelas mamangavas (Xylocopa sp. e outras espécies), principalmente se houver pomares de maracujazeiros de outros cultivares na vizinhança. A polinização manual deve ser realizada no período da tarde, horário em que as flores do maracujazeiro estão abertas, geralmente após as 14 horas, coletando o pólen das anteras das flores das matrizes selecionadas e aplicando-o no estigma das flores das outras plantas selecionadas, garantindo o cruzamento aleatório. Após, essas flores polinizadas devem ser ensacadas e os sacos devem ser mantidos até os frutos alcançarem 6 a $8 \mathrm{~cm}$ de diâmetro. Depois, os sacos de papel são removidos e os frutos ficam cobertos com sacos tipo raschel (Figura 3), diminuindo o risco de serem extraviados na colheita.

A troca de sementes do mesmo cultivar de maracujá-azedo entre diferentes produtores favorece a sua manutenção, já que existe a possibilidade de perda de alelos de interesse devido a efeitos do selecionador (produtor) e da seleção natural nos distintos ambientes. Deve-se indicar a troca de sementes entre produtores que realizem o mesmo método de seleção.

\section{Marcadores morfológicos que auxilliam no processo de seleção}

Durante as observações realizadas para a seleção de plantas matrizes para a obtenção de sementes, alguns marcadores morfológicos podem ser utilizados como ferramentas complementares para tomada de decisão. Plantas com maior presença de antocianinas (principalmente nos botões florais, ramos, pecíolos e sépalas roxas) são menos suscetíveis às doenças e mais produtivas. As plantas com folhas maiores são mais tardias e menos produtivas, por apresentarem vigor excessivo.

\section{Considerações finais}

A base para a produção de mudas é a utilização de sementes de alta qualidade genética, proporcionando a instalação de pomares mais produtivos e saudáveis. A obtenção de plantas com superioridade genética pode implicar na redução de aplicação de agrotóxicos e menor risco de danos ao ambiente.

\section{Referências}

BORÉM, A.; MIRANDA, G. V. Melhoramento de plantas. 5. ed. Viçosa: UFV, 2009. 529p.

BRUCKNER, C. H.; MELETTI, L. M. M.; OTONI, W. C.; ZERBINI JUNIOR, F. M. Maracujazeiro. In: BRUCKNER, C. H. Melhoramento de fruteiras tropicais. Viçosa: UFV, 2002. p.373409.

GOULART JUNIOR, R.; MONDARDO, M.; PETRY, H. B. Caracterização da produção e comercialização do maracujá: estudo na mesorregião do sul catarinense. In: CONGRESSO DA SOCIEDADE BRASILEIRA DE ECONOMIA, ADMINISTRAÇÃO E SOCIOLOGIA RURAL, 55., 2017, Santa Maria. Anais [...] Santa Maria: Sober, 2017.

JESUS, O. N.; FALEIRO, F. G.; JUNQUEIRA, K. P.; GIRARDI, E. A.; ROSA, R. C. C.; PETRY, H. B. Cultivares comerciais de maracujá-azedo (Passiflora edulis Sims) no Brasil. In: JUNGHANS, T. G.; JESUS, O. N. Maracujá: do cultivo à comercialização. Brasília, DF: Embrapa, 2017. p.9-58.

JUNGHANS, T. G.; ROSA, R. C. C.; GIRARDI, E. A. Produção de mudas de maracujazeiro. In: JUNGHANS, T. G.; JESUS, O. N. Maracujá: do cultivo à comercialização. Brasília, DF: Embrapa, 2017. p.101-114.

MARTINS, M. R.; REIS, M. C.; MENDES NETO, J. A.; GUSMÃO, L. L.; GOMES, J. J. A. Influência de diferentes métodos de remoção do arilo na germinação de sementes de maracujazeiro-amarelo (Passiflora edulis Sims F. flavicarpa Deg.). Revista da FZVA, Uruguaiana, v. 13, n. 2, 2006. p.28-38.

MELETTI, L. M. M.; SOARES-SCOTT, M. D.; BERNACCI, L. C.; PASSOS, I. R. S. Melhoramento genético do maracujá: passado e futuro. In: FALEIRO, F. G.; JUNQUEIRA, N. T. V.; BRAGAS, M. F. Maracujá: germoplasma e melhoramento genético. Planaltina: Embrapa, 2005. p.55-75.

SOUZA, M. M.; PEREIRA, T. N. S. Biologia da reprodução em maracujazeiro amarelo e sua importância para a produção comercial de frutos. In: PIRES, M. M.; SÃO JOSÉ, A. R.; CONCEIÇÃO, A. O. Maracujá: avanços tecnológicos e sustentabilidade. Ilhéus: Editus. 2011. p.175-202. 